\title{
Energy flexibility potential of domestic hot water systems in apartment buildings
}

\author{
Ase Lekang Sørensen ${ }^{1,2^{*}}$, Harald Taxt Walnum ${ }^{1}$, Igor Sartori ${ }^{1}$, and Inger Andresen ${ }^{2}$ \\ ${ }^{1}$ SINTEF, Department of Architectural Engineering, P.O. Box 124 Blindern, 0314 Oslo, Norway \\ ${ }^{2}$ Norwegian University of Science and Technology (NTNU), Department of Architecture and Technology, 7491 Trondheim, Norway
}

\begin{abstract}
Domestic Hot Water (DHW) storage tanks are identified as a main source of flexible energy use in buildings. As a basis for energy management in apartment buildings, this paper describes the aggregated DHW use in a case building, and analyses the potential for DHW energy flexibility by simulating different control options. The case study for the work is an apartment building in Oslo with 56 apartments and a shared DHW system. Energy measurements are available for consumed hot water, hot water circulation, and energy supplied to the DHW tanks. The measurements are presented with minute, hourly and daily values. Aggregated daily energy use for the consumed hot water is in average $362 \mathrm{kWh}$, while the energy supplied is $555 \mathrm{kWh}$. The potential for energy flexibility is analysed for a base case and for four different rule-based control options: Power limitation, Spot price savings, Flexibility sale and Solar energy. Economic consequences of the control options are compared. With the Norwegian tariff structure, maximum hourly power use has the main impact on the cost. Control systems that aim to reduce the maximum power use may be combined with spot price savings or to offer end-user flexibility services to the grid.
\end{abstract}

\section{Introduction}

\subsection{Flexibility potential of DHW systems}

Moving towards zero emission buildings and neighbourhoods, thermal and electric energy loads can be managed in a flexible way to achieve i.e. reduced power peaks, reduced energy use, reduced $\mathrm{CO}_{2-}$ emissions, and increased self-consumption of locally produced energy. Further, smart management of building loads can provide energy flexibility services to energy companies.

Domestic Hot Water (DHW) storage tanks are identified as a main source of flexible energy use in buildings [1]. As buildings are becoming more energy efficient, the share of DHW energy is increasing. However, so far, there has been relatively limited efforts in the field of energy-efficient DHW [2].

With demand side management (DSM) it is possible to influence the end-use of energy in a number of ways, by reducing (peak shaving), increasing (valley filling) or rescheduling (load shifting) the energy demand [3]. For the DHW system, load shifting of the energy profile is possible, i.e. by preheating the storage tanks or delaying the heating of the hot water. The flexibility capacity of DHW systems is largely based on the volume of the storage tank [1]. When storing DHW there are heat losses; [2] found ranges from $2 \%$ to $36 \%$ heat losses in the storage tanks depending on the system solution. The VarmtVann2030 project found annual heat loss values in the range of $4 \mathrm{kWh}$ per litre stored [4].
DHW use in individual households has been analysed by e.g. [5], [6], [7] and [8]. Balint and Kazmi [5] analysed energy flexibility of DHW, where each household has a 200 litre storage tank. They found that the energy flexibility is influenced by ambient conditions, control algorithm and occupant behaviour. Ericson [6] analysed data from 475 households, where electric water heaters were automatically disconnected during peak periods of the day. The results show reductions in electricity use during the disconnections, but also indicate a risk for new system peaks if several DHW tanks are reconnected all at once. [7] analysed the stochastic nature of DHW demand in residential houses, used machine learning to predict the behaviour in 6 individual houses, and investigated the potential for energy reduction by an adapting hot water system. [8] analysed DHW consumption profiles from 95 residential houses and aggregated information. They found that the aggregate consumption profile is more predictable than individual consumption profiles.

Many apartment buildings have shared electric DHW tanks in a heating central, where load shifting of the electricity use could be possible. DHW use in buildings is affected by user behaviour [9]. Compared to DHW use in individual households, aggregated DHW use in apartment buildings is expected to be more predictable, influenced by parameters such as time of day, day of the week, months, and holiday periods [10].

As a basis for energy management in Norwegian apartment blocks, this study analyses DHW measurements in a typical apartment building located in Oslo. The work gives general recommendations for

\footnotetext{
* Corresponding author: ase.sorensen@sintef.no
} 
possible rule-based control (RBC) options, utilizing the energy flexibility potential. The research question of the work is: How can an apartment building reduce energy costs by shifting aggregated DHW energy loads in time, provided a limited storage volume? The analysis will also provide the basis for more advanced analysis planned, as described in section 3.2.

\subsection{The case study apartment building}

The case study for the work is an apartment building in Oslo with 56 apartments and in total $3,752 \mathrm{~m}^{2}$ heated floor area. Each apartment has a floor area of $67 \mathrm{~m}^{2}$ and has two bedrooms.

DHW is heated by a local heating network based on heat pumps (preheating) and electricity, see Table 1. The heating and storage capacities are dimensioned to fulfil the residents need for DHW, with temperature-based control of the DHW tanks, but there is otherwise no active DSM of the DHW system. The DHW is supplied to the apartments from a technical room in the basement. DHW is permanently circulated in pipes on the basement level, to keep the water hot, compensating for heat losses. There is no circulation system from the basement and up to each apartment.

Energy measurements are available on an aggregated level, and include energy need for DHW (without losses, as defined by [11]), energy losses in the DHW circulation, and energy supplied to the DHW tanks (to cover DHW energy need and all losses). In this article, the total DHW heating and storage capacities are analysed, not separating between the preheating and electricity heating systems.

Table 1. DHW heating and storage capacities in the case.

\begin{tabular}{|c|c|c|c|}
\hline Source & $\begin{array}{c}\text { Capacity } \\
(\mathbf{k W})\end{array}$ & $\begin{array}{c}\text { Storage } \\
\text { (litre) }\end{array}$ & $\begin{array}{c}\text { Storage } \\
(\mathbf{k W h )} \text { * }\end{array}$ \\
\hline $\begin{array}{c}\text { Preheating via } \\
\text { heat exchanger }\end{array}$ & 60 & $\begin{array}{c}(4 \times 400) \\
1,600\end{array}$ & 96 \\
\hline Electricity & $\begin{array}{c}(3 \times 14) \\
42\end{array}$ & $\begin{array}{c}(3 \times 400) \\
1,200\end{array}$ & 72 \\
\hline $\begin{array}{c}\text { Total values } \\
\text { (used in article) }\end{array}$ & $\mathbf{1 0 2}$ & $\mathbf{2 , 8 0 0}$ & $\mathbf{1 6 8}$ \\
\hline
\end{tabular}

* Storage multiplied by accumulation factor $0.06 \mathrm{kWh} /$ litre.

\subsection{Economic motivation for energy flexibility}

This section describes existing tariff structure and economic conditions, which may motivate building owners to realize their DHW energy flexibility potential.

1) Power limitation: In Norway, electricity production and transmission capacity during peak-load hours is a main concern for the distribution grid [6], especially during winter months. Therefore, larger customers usually pay hourly power tariffs, e.g. if they exceed 100,000 kWh annual electricity use behind a meter. For the case building, the power tariffs are monthly, with tariffs varying from 2.2 euros $/ \mathrm{kW}$ (7 summer months), 6.7 euros/kW (2 spring/autumn months) and 12 euros/kW (3 winter months) [12] (1 euro $=10 \mathrm{NOK})$.
2) Spot price savings: Day-ahead spot prices are available from NordPool [13]. This is a market price of power, determined by supply and demand. The prices are normally higher during peak load hours, in the morning and afternoon. For most days during the year, the hourly price differences during a day are rather small. However, there are exceptions, where the spot prices increase substantially for a few hours during the day. For example, during the winter day 12 February 2021, the hourly prices increased from about 0.05 euro/kWh during the night hours to about 0.25 euro/kWh during the morning peak. Figure 1 shows normalized spot prices for each day in the period January 2019 to February 2021, the prices during the 23days data period used in this article, as well as the prices during corresponding 23 dates in 2021 . In the figure, the absolute price difference for each hour is shown, as the difference between the spot prices each hour and the average hourly spot price during the same day.

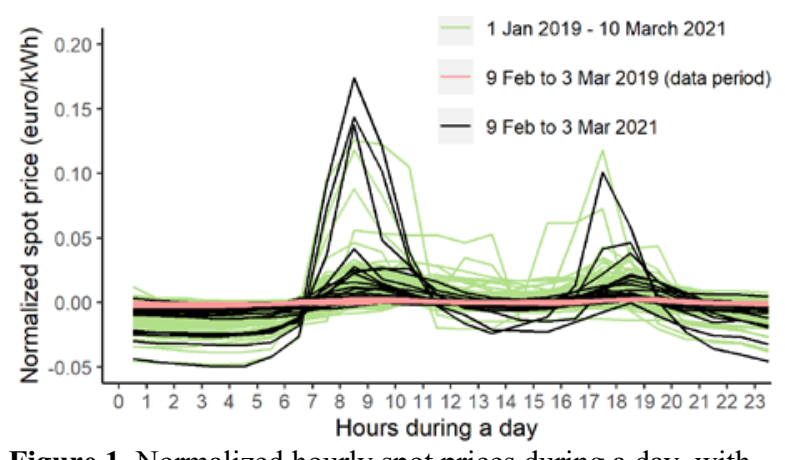

Figure 1. Normalized hourly spot prices during a day, with line colours illustrating three time periods.

3) Energy flexibility services to energy companies: End-user flexibility may become valuable for the Distribution System Operator (DSO). A market may be developed, where building owners are paid for not using energy during peak hours. However, it is difficult to quantify the value of such flexibility services, since related tariffs are not yet existing in Norway. The project EMPOWER [14] presents a local energy market concept, with compensation in the form of a strike price and an activation reward. In an example, they suggest 11 euros strike price and 4 euros activation reward for a 1.5 $\mathrm{kW}$ flexible load, with given activation criteria (up to 2.5 hours activation mornings and evenings weekdays).

4) Increased self-consumption of locally produced energy: If there are solar energy supply systems on-site, there is an economic advantage of using the energy in the building, including thermal energy from solar collectors and electricity from photovoltaic (PV) systems. For thermal solar energy, unused energy has no value (given that it cannot be exported). For solar electricity, within the Norwegian tariff structure, the income of electricity exported to the grid is mainly the spot price, while the price of electricity imported from the grid is about the double, including also grid costs and taxes [15]. It is therefore beneficial to shift DHW loads to the daytime (direct use of solar energy) or to store hot water in DHW tanks. There is no solar energy technologies installed in the case building, but the article 
analyses the effects of solar electricity from a theoretical PV-system.

5) Energy use: Utilizing the flexibility of a DHW system may increase the use of the storage system, which would increase the heat losses of the system. The variable electricity price for end-use customers is in the range of 0.08 euro $/ \mathrm{kWh}$, including spot price and taxes [16]. If the annual heat losses related to the storage tanks are about $4 \mathrm{kWh} /$ litre [4], the energy costs of an additional litre stored is around 0.32 euro/year. The annual heat loss for the current 2,800 litre heat storage in the case building may thus cost about 900 euros/year.

6) Investment costs and technical lifetime of DHW systems: Use of flexibility will also change the operation of the energy systems, which may change their technical lifetime [17]. For example, more constant power delivered from heat pumps may increase their lifetimes and may also reduce the capacity size needed for heat pumps and heat exchangers. However, such systems may require increased storage volume. Also, investments in monitoring equipment and building energy management systems (EMS) may be needed. [18] analysed practical performance of heat pump systems, finding universal challenges such as over-sized capacity design and unreasonable control strategies. To improve the energy efficiency, they suggest decentralized and reasonable system design, as well as accurate and efficient control strategies.

In this article, the economic consequences of 1) to 4) are included, while the consequences of 5) and 6) are not analysed.

\section{Nomenclature}

\begin{tabular}{|l|l|}
\hline CO & Control option \\
\hline CHW & Consumed hot water \\
\hline DHW & Domestic hot water \\
\hline DaySES & Daily supplied energy setpoint \\
\hline DSM & Demand side management \\
\hline DSO & Distribution system operator \\
\hline EMS & Energy management system \\
\hline HWC & Hot water circulation \\
\hline RBC & Rule-based control \\
\hline SoC & State of charge \\
\hline
\end{tabular}

\section{Methodology}

\subsection{Method for DHW measurements}

DHW measurements for this study were extracted from the following sources: The project VarmtVann2030 [19] performed a measurement campaign where energy for consumed hot water ( $\mathrm{CHW})$ and distribution losses in the hot water circulation (HWC) were measured. The EMS in the building measures energy supplied to the DHW tanks.

The measurement campaign lasted for 7 weeks, from 16 January to 6 March 2019. Flow and temperature measurements were performed on the main supply pipe for the apartment building. Clamp-on ultrasonic flow meters were used for flow measurement and Type-T thermocouples where mounted on the pipe wall. Flow rates and temperatures were measured with an interval of 1 second, and then averaged to 2 seconds before analysis. Measurement equipment and energy calculations are described in [20].

Energy supplied to the DHW tanks was measured hourly. The measurements are available for 3 full weeks and 4 weekends, from 9 February to 3 March. In the EMS, both thermal energy (preheating) and electricity to the DHW tanks were measured, and the total hourly energy supplied is used in these analysis.

Due to the storage tanks, there is a time difference between CHW and energy supplied. In addition, there is an absolute difference between energy supplied and energy needed for CHW and HWC. This difference is calculated as the heat losses in the technical room, and is related to heat exchanger, storage, valves, pipes, etc.

\subsection{Method for DHW energy analysis}

The following data are used in the energy analysis: 50 days measurement-period (16.01 - 06.03.2019):

- CHW, resampled to 1 minute and 1 hour time steps, - HWC, resampled to 1 minute and 1 hour time steps, 23 days measurement-period (09.02 - 03.03.2019):

- Energy supplied (sum of preheating and electricity), 1 hour time steps,

- Heat losses in the technical room (calculated difference as described above), 1 hour time steps.

Calendar data were added to the energy data, such as time of day and weekdays. DHW energy need and supplied energy are analysed. For CHW and HWC, the time steps of 1 minute and 1 hour are compared. For the heat losses in the technical room, the hourly analyses show average heat losses, not heat losses hour-by-hour, since the hourly values includes the time-delay between CHW and supplied energy.

\subsection{Control options for utilizing flexibility}

The potential for energy flexibility is analysed by simulating a base case and four different control options (COs), named control option 1 "Power limitation", control option 2 "Spot price savings", control option 3 "Flexibility sale", and control option 4 "Solar energy". The control options are rule-based with additional constraints [21], aiming to account for physical limitations of the systems, and to make sure DHW is always available for the users.

Input parameters for the control options are:

- CHW (all COs): Hourly values, 23-day period.

- HWC (all COs): Hourly values, 23-day period.

- Heat loss in technical room (all COs): Hourly average heat loss value is used for all hours: $4.7 \mathrm{~kW}$.

- Daily supplied energy setpoint, DaySES (all COs): Assumed maximum energy supply during a day, set $10 \%$ above the measured value of $613 \mathrm{kWh}: 672 \mathrm{kWh}$ per day.

- Power limitation setpoint: Because of the existing hourly power tariffs, there is a power limitation in most of the COs (except the base case and the CO 2 case): 
- Base case: No limitation, except by actual installed total capacity: $102 \mathrm{kWh} / \mathrm{h}$.

- CO 1: Even distribution DaySES: 672/24=28 $\mathrm{kWh} / \mathrm{h}$.

- CO 2: The spot prices are divided into three levels each day: 1) Low-price level: 12 hours, limited by actual installed capacity $(102 \mathrm{kWh} / \mathrm{h}), 2)$ Mediumprice level: 8 hours, limited to energy use that hour (no energy is supplied to the storage tanks), and 3) High-price level: 4 hours, no energy supply.

- CO 3: Two peak load hours with no supplied energy: One in the morning (from 07:00 weekdays and 10:00 weekends) and one in the afternoon (from 16:00 all days). Even distribution of DaySES on the remaining hours: $672 / 22=30.5 \mathrm{kWh} / \mathrm{h}$.

- CO 4: Solar electricity is prioritized, when available. A $50 \mathrm{~kW}_{\mathrm{p}}$ system is assumed, based on a solar map for Oslo [22]. Hourly electricity generation is simulated for 2019, using the tool renewables.ninja [23] (Dataset MERRA-2, 0.1 system loss, $30^{\circ}$ tilt, $135^{\circ}$ azimuth). In addition: Even distribution of DaySES: 672/24=28 kWh $/ \mathrm{h}$.

- State of charge (SoC) storage tank (all COs): Limited to the total storage volume available in the technical room: $168 \mathrm{kWh}$. For the first hour, the storage volume is full. Then, calculated for each hour (i) as:

$$
E_{\text {tank }(i)}=E_{\text {tank }(i-1)}+E_{P V(i)}+E_{\text {setpoint }(i)}-E_{C H W(i)}-E_{H W C(i)}-E_{\text {losses }(i)}
$$

Condition: If $E_{\text {tank }(i)}>E_{\text {tank-cap }}$ then $E_{\text {tank }(i)}=E_{\text {tank-cap }}$

$E_{\text {setpoint }(i)}$ is the hourly power limitation setpoint, while $E_{\text {tank-cap }}$ is the storage tank capacity. Hourly solar energy $\left(E_{P V(i)}\right)$ is zero for all COs except $\mathrm{CO} 4$.

- Energy supply (varies with the CO): Hourly energy supply, calculated for each hour (i) as:

$E_{\text {supply }(i)}=E_{\text {tank }(i)}-E_{\text {tank }(i-1)}-E_{P V(i)}+E_{C H W(i)}+E_{H W C(i)}+E_{\text {losses (i) (2) }}$

\section{Results and discussion}

\subsection{DHW energy need and supplied energy}

This section describes the actual energy need and supplied energy to the DHW tanks in the case building. Figure 2 shows CHW and HWC during the 50-days measurement period, and supplied energy during the 23days measurement period. Figure 3 shows the duration curve for $\mathrm{CHW}$ and $\mathrm{HWC}$ separately, comparing minute and hourly time steps. Comparing the time steps, the max. power averaged during a minute is about 3 times higher than the max. power averaged during an hour. For hourly resolution of $\mathrm{CHW}$, the max power is $53.3 \mathrm{~kW}$, while the 95 -percentile is $33.9 \mathrm{~kW}$. For the minute resolution of $\mathrm{CHW}$, the max power is $171.9 \mathrm{~kW}$, while the 95 -percentile is $49.6 \mathrm{~kW}$. The substantial variations within one hour should be taken into account when analysing hourly averages and indeed when dimensioning DHW systems and preparing control systems.

Table 2 shows hourly and daily values for $\mathrm{CHW}$, HWC, supplied energy, and heat losses. The HWCvalues show that energy losses in the distribution are fairly constant during the day. The total heat losses are $35 \%$ of the supplied energy. Figure 4 shows $\mathrm{CHW}$, HWC and supplied energy each day during the 50 days measurement period. There are not very large daily variations. The daily $\mathrm{CHW}$ values vary from 276 to 436 kWh per day during the period, while HWC values vary from 68 to $94 \mathrm{kWh}$ per day. There was a holiday period from 18 to 24 February, but it appears that there is not any significant change in DHW use.

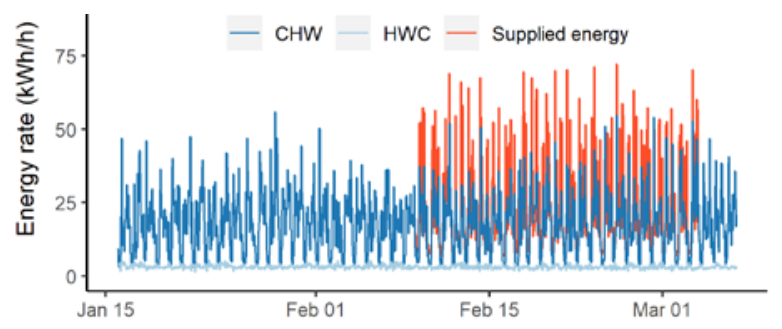

Figure 2. CHW, HWC and supplied energy on a timeline with 1 hour time-steps (data series are stacked in columns).

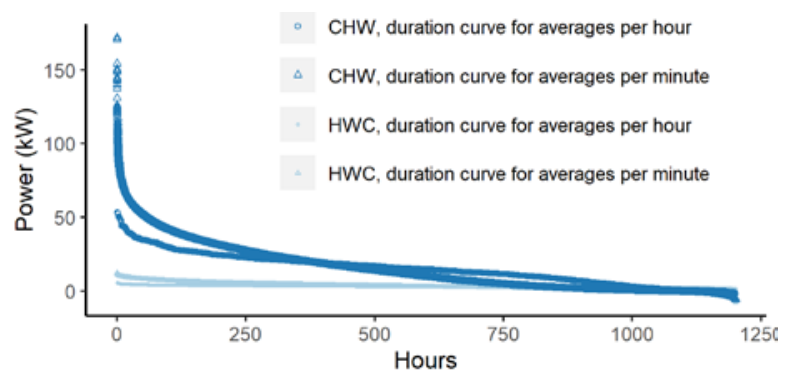

Figure 3. Duration curve for CHW and HWC separately. Comparing 1 minute and 1 hour time-steps.

Table 2. Hourly and daily values for CHW, HWC, supplied energy and heat losses.

\begin{tabular}{|c|c|c|c|c|c|}
\hline DHW (kWh) & $\begin{array}{c}\text { Average } \\
\text { hourly }\end{array}$ & $\begin{array}{c}95- \\
\text { percentile } \\
\text { hourly }\end{array}$ & $\begin{array}{c}\text { Max } \\
\text { hourly }\end{array}$ & $\begin{array}{c}\text { Average } \\
\text { daily }\end{array}$ & $\begin{array}{c}\text { Max } \\
\text { daily }\end{array}$ \\
\hline CHW & 15.1 & 33.9 & 53.3 & 362 & 436 \\
\hline HWC & 3.3 & 4.4 & 5.6 & 78 & 94 \\
\hline Supplied & 23.1 & 54.6 & 72.1 & 555 & 613 \\
\hline Heat losses & 4.7 & - & - & 112 & 142 \\
\hline
\end{tabular}

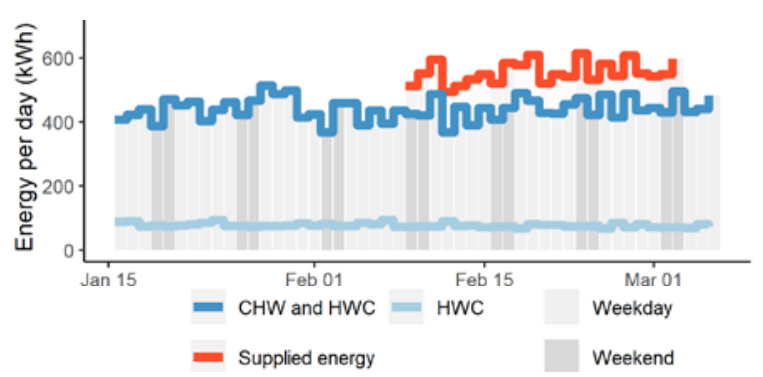

Figure 4. Daily CHW, HWC and supplied energy during weekdays and weekends.

Hourly average values are shown in the daily profile in Figure 5. CHW, HWC, heat losses, and supplied energy are shown separately, with their individual $90 \%$ confidence interval. For heat losses, an average value is shown. The daily values show an increased CHW during the morning, from about 06:00 during the weekdays and about during 08:00 weekends. There is a morning and afternoon peak, as also observed in other apartment 
buildings [24], but also the DHW uses during other daytime hours are quite high. An explanation for this could be that residents with small children or elderly are overrepresented, which is reasonable given that the apartments have two bedrooms only. If so, a higher share of the residents may be home during daytime, compared to other buildings with more mixed or larger apartment sizes. For CHW, Table 3 provides more details, with hourly average values during weekdays and weekends.

In the case study, supplied energy during peak hours is higher than the CHW, even though DHW tanks are present. This is explained by the design of the preheating control system. Using the storage capacity actively, it may be possible to shift loads from peak hours to offpeak hours. This is further investigated in the next section.

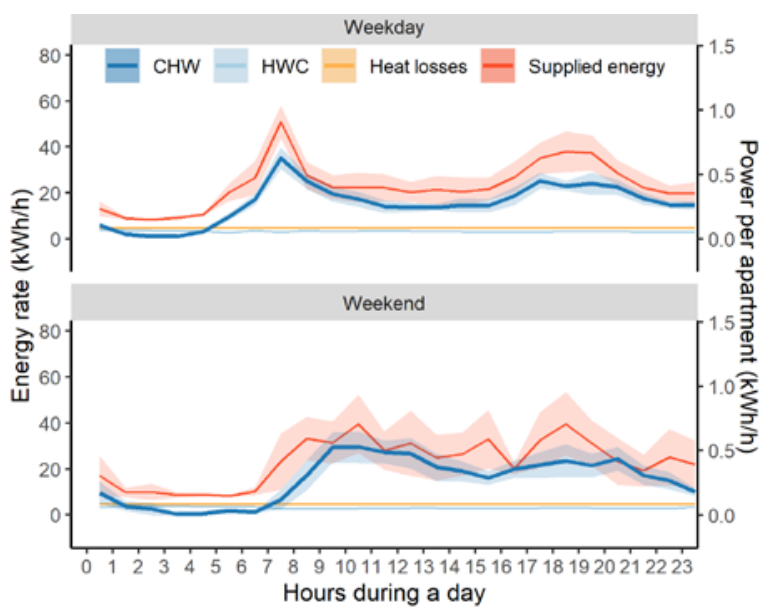

Figure 5. Average daily profiles for CHW, HWC, heat losses, and supplied energy, shown separately, with their individual $90 \%$ confidence interval (1 hour time-steps).

Table 3. Average CHW for weekday/weekend hours (kWh).

\begin{tabular}{|c|c|c|c|c|c|}
\hline $\begin{array}{c}\text { Daily } \\
\text { hour }\end{array}$ & $\begin{array}{c}\text { Week- } \\
\text { days }\end{array}$ & $\begin{array}{c}\text { Week- } \\
\text { end }\end{array}$ & $\begin{array}{c}\text { Daily } \\
\text { hour }\end{array}$ & $\begin{array}{c}\text { Week- } \\
\text { days }\end{array}$ & $\begin{array}{c}\text { Week- } \\
\text { end }\end{array}$ \\
\hline $\mathbf{0 0 - 0 1}$ & 6.7 & 9.8 & $\mathbf{1 2 - 1 3}$ & 12.3 & 24.7 \\
\hline $\mathbf{0 1 - 0 2}$ & 2.3 & 5.5 & $\mathbf{1 3 - 1 4}$ & 13.1 & 21.1 \\
\hline $\mathbf{0 2 - 0 3}$ & 1.1 & 2.6 & $\mathbf{1 4 - 1 5}$ & 16.2 & 18.8 \\
\hline $\mathbf{0 3 - 0 4}$ & 0.8 & 0.6 & $\mathbf{1 5 - 1 6}$ & 16.2 & 17.0 \\
\hline $\mathbf{0 4 - 0 5}$ & 2.6 & 0.4 & $\mathbf{1 6 - 1 7}$ & 20.9 & 18.6 \\
\hline $\mathbf{0 5 - 0 6}$ & 9.0 & 1.9 & $\mathbf{1 7 - 1 8}$ & 25.0 & 21.4 \\
\hline $\mathbf{0 6 - 0 7}$ & 16.8 & 1.0 & $\mathbf{1 8 - 1 9}$ & 24.5 & 19.6 \\
\hline $\mathbf{0 7 - 0 8}$ & 31.8 & 6.6 & $\mathbf{1 9 - 2 0}$ & 24.2 & 20.3 \\
\hline $\mathbf{0 8 - 0 9}$ & 21.6 & 17.4 & $\mathbf{2 0 - 2 1}$ & 24.0 & 22.7 \\
\hline $\mathbf{0 9 - 1 0}$ & 17.2 & 27.2 & $\mathbf{2 1 - 2 2}$ & 17.2 & 18.4 \\
\hline $\mathbf{1 0 - 1 1}$ & 16.4 & 31.0 & $\mathbf{2 2 - 2 3}$ & 16.3 & 14.4 \\
\hline $\mathbf{1 1 - 1 2}$ & 12.7 & 28.3 & $\mathbf{2 3 - 2 4}$ & 14.8 & 9.8 \\
\hline \multicolumn{7}{|c|}{ Average daily CHW (kWh/day): } & $\mathbf{3 6 3 . 9}$ & $\mathbf{3 5 9 . 1}$ \\
\hline
\end{tabular}

\subsection{Energy flexibility potential of DHW systems}

This section analyses the potential for energy flexibility by simulating a base case and four control options. For each option, the average daily profile and an example day are shown in Figure 6 and Figure 7, while Table 4 provides some key results. The average day has a CHW demand of $367 \mathrm{kWh}$ and a max. hourly
CHW load of $52.5 \mathrm{kWh} / \mathrm{h}$, based on the 23-day measurement period. Including losses, the daily demand is $554.8 \mathrm{kWh}$ and the max. hourly load is $59.3 \mathrm{kWh} / \mathrm{h}$. The example day Sunday 3 March 2019 is chosen, since it has the highest daily demand (606 kWh incl. losses) and the third highest hourly load $(57.3 \mathrm{kWh} / \mathrm{h})$ during the 23-day period.

For the base case, the heat production capacity of $102 \mathrm{kWh} / \mathrm{h}$ can deliver all needed energy, hour-by-hour. The storage capacity therefore remains at maximum level on an hourly basis. The max. hourly energy supply is $59.3 \mathrm{kWh} / \mathrm{h}$.

CO 1 "Power limitation" aims to distribute the supplied energy evenly through the day, to reduce the power tariff costs. For both the average day and the example day, the supplied energy is limited by the DHW tank volume during night-hours. The minimum SoC for the storage tank during the 23-day period is $65.5 \mathrm{kWh}$ (39\%), which implies that the tank volume is sufficient. If it becomes necessary to increase the hourly energy supply, this increase should happen slowly, since large power jumps over a short period has higher economical costs than a smaller power increase during a longer period. Since hourly values are analysed, a safety margin should be considered, to make sure that the needed energy can be provided within the hour. This is illustrated in Figure 8, showing the example day with minute timesteps, which can be directly compared with CO 1 in Figure 7. A DWH tank may be emptied due to variations within the hour, even though the tank is large enough for the hourly averages.

With CO 2 "Spot price savings", the supplied energy is distributed according to the day-ahead spot prices. The spot prices vary during the day, with higher spot prices during energy peak periods. With CO 2, this results in less energy production during hours with DHW demand, both for the average day and the example day. The result is that CO 2 struggles to supply the needed energy, given the available DHW storage. With all the heat production capacity available, the minimum SoC for the storage tank during the period is $21.8 \mathrm{kWh}$ $(13 \%)$. This is during a day where all the four high-price level hours (with no energy supply) are in sequence. The maximum hourly load is high, since there are no limitations $(102 \mathrm{kWh} / \mathrm{h})$. Also for this control option, a maximum level could be set for the hourly energy supply. In addition, other conditions could be tested, e.g. limiting the number of high-price level hours in sequence, reducing the number of hours with high-price or medium-price level, or increasing the available storage volume.

With CO 3 "Flexibility sale", there is no energy supply during 2 peak hours. Like for CO 1, the power level is limited by the DHW tank volume during nighthours. The minimum SoC for the storage tank during the period is $35.8 \mathrm{kWh}(21 \%)$, which means that it may be necessary to increase either the hourly energy supply or the tank volume in order to provide flexibility services every day. Another option is to only offer flexibility services when sufficient capacity is available, if this becomes a possible option within the flexibility market. 


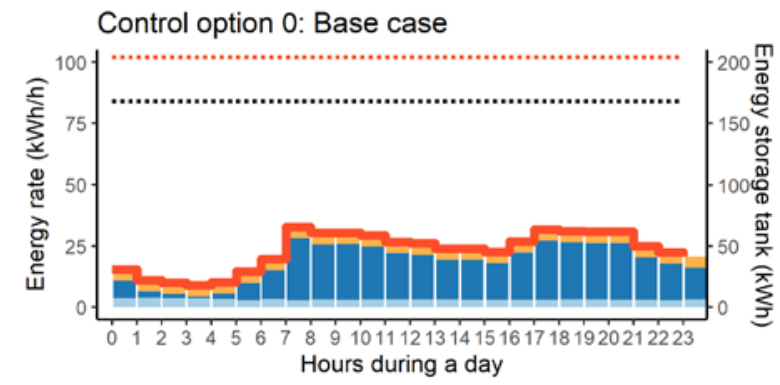

Control option 1: Power limitation

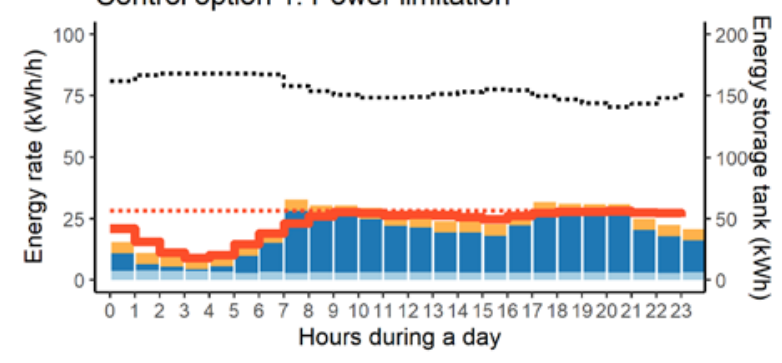

Control option 2: Spot price savings

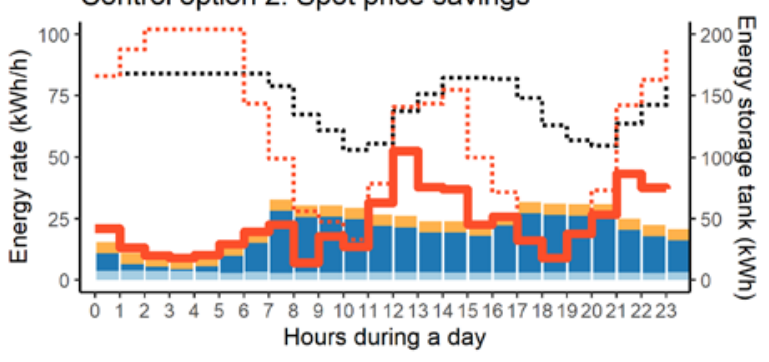

Control option 3: Flexibility sale

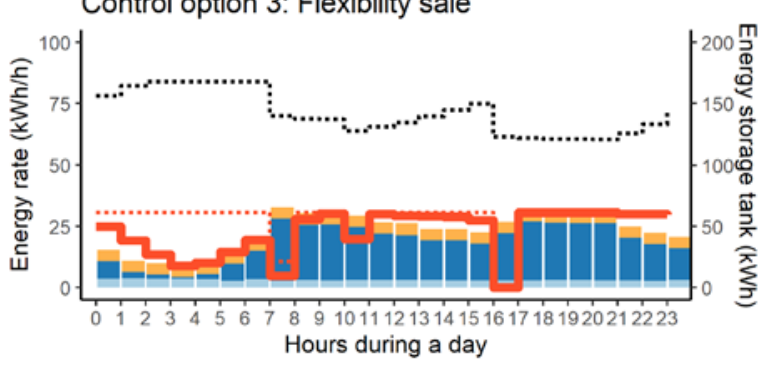

Control option 4: Solar energi

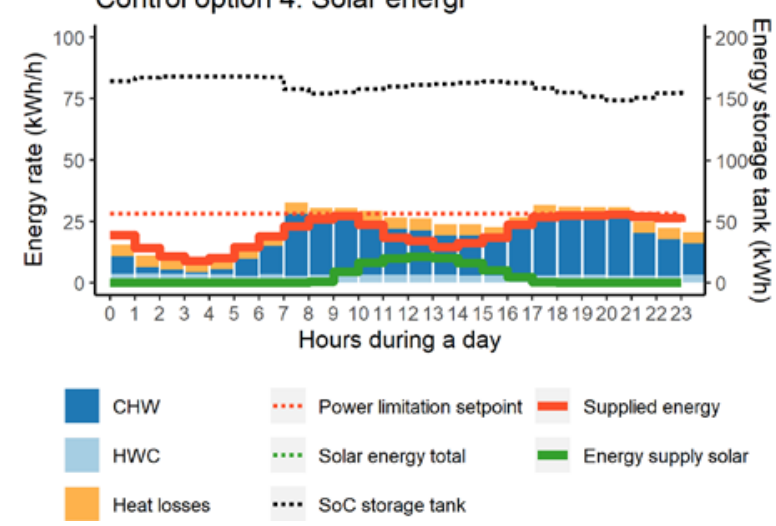

Figure 6. Average daily profiles for the control strategies.

CO 4 "Solar energy" is like CO 1, but with a PVsystem added. The solar electricity is used directly, either to supply the DHW demand or to be stored in the tanks (limited by tank capacity). Solar electricity is prioritized when available, and the power limitation in

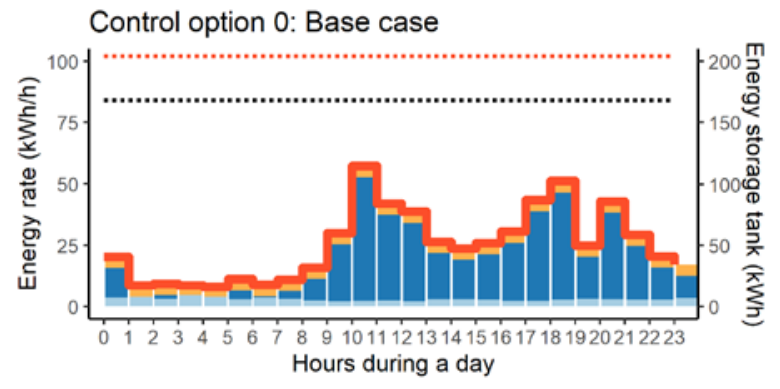

Control option 1: Power limitation

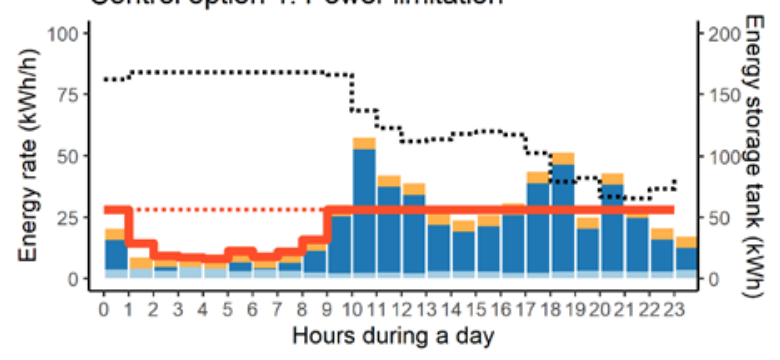

Control option 2: Spot price savings

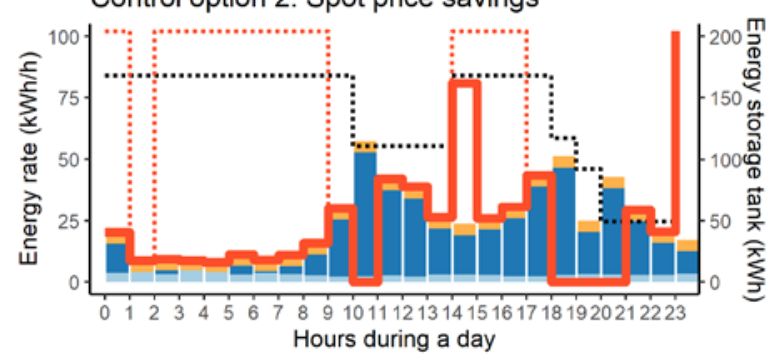

Control option 3: Flexibility sale

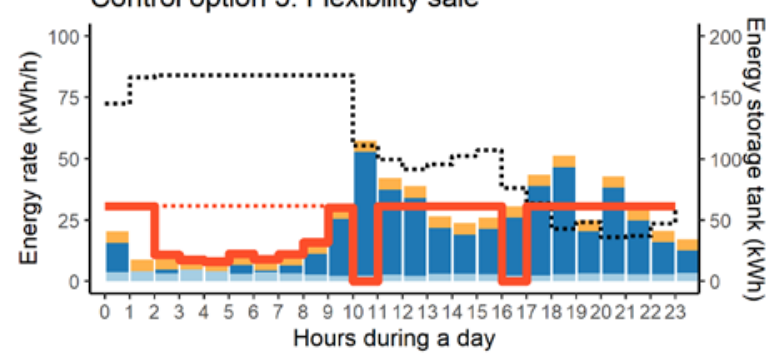

Control option 4: Solar energi

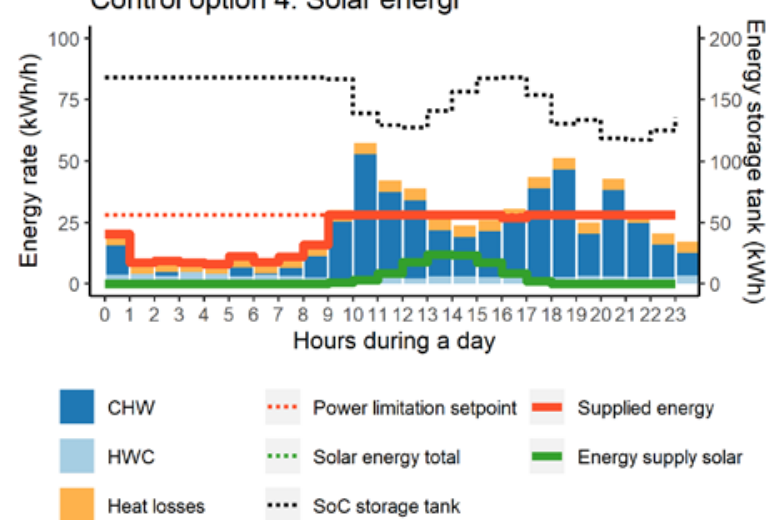

Figure 7. Daily profiles for example day 2019-03-03.

CO 1 is relevant for grid electricity only, not solar electricity. In the 23-day period, the average PV generation is $62 \mathrm{kWh}$ per day (Figure 6). The minimum SoC for the storage tank is $113 \mathrm{kWh}(67 \%)$. The daily $\mathrm{PV}$ generation March 3 is $53 \mathrm{kWh}$ (Figure 7). During the 
year 2019, the average daily PV generation is $123 \mathrm{kWh}$, with maximum $341 \mathrm{kWh} /$ day.

Table 4. Analysis of control strategies (23-days period)

\begin{tabular}{|c|c|c|c|c|}
\hline & $\begin{array}{c}\text { Energy } \\
\text { supply } \\
(\mathrm{kWh})\end{array}$ & $\begin{array}{c}\text { Power } \\
\text { max } \\
(\mathrm{kW})\end{array}$ & $\begin{array}{c}\text { Average } \\
\text { SoC storage } \\
(\mathrm{kWh})\end{array}$ & $\begin{array}{c}\text { Min. SoC } \\
\text { storage } \\
(\mathrm{kWh})\end{array}$ \\
\hline $\mathrm{CO} 0$ & 12,760 & 59.3 & 168 & 168 \\
\hline $\mathrm{CO} 1$ & 12,676 & 28.0 & 154.8 & $65.5(39 \%)$ \\
\hline $\mathrm{CO} 2$ & 12,725 & 102.0 & 146.4 & $21.8(13 \%)$ \\
\hline $\mathrm{CO} 3$ & 12,652 & 30.5 & 142.2 & $35.8(21 \%)$ \\
\hline $\mathrm{CO} 4$ & $\begin{array}{c}11,349 \\
+\mathrm{PV} 1,378\end{array}$ & 28.0 & 160.2 & $113(67 \%)$ \\
\hline
\end{tabular}

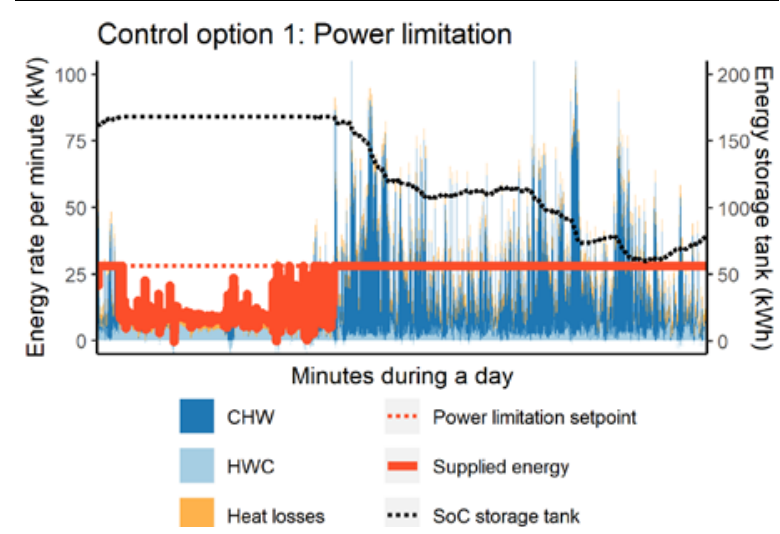

Figure 8. Daily profile for example day 2019-03-03, with minute timesteps.

Table 5. Economic consequences of the control strategies

\begin{tabular}{|c|c|c|c|c|}
\hline & \multirow{2}{*}{$\begin{array}{c}\text { Power tariffs } \\
(€ / \text { month) } \\
\text { summer-winter }\end{array}$} & \multicolumn{2}{|c|}{$\begin{array}{c}\text { Spot-price } \\
(€ / 23 \text { days })\end{array}$} & \multirow{2}{*}{$\begin{array}{c}\text { Other } \\
(€ / 23 \text { days })\end{array}$} \\
\cline { 3 - 4 } & $130-712$ & 553 & 669 & \\
\hline CO 0 & $130-719$ & 2021 & \\
\hline CO 1 & $62-336(47 \%)$ & $548(-5)$ & $653(-16)$ & \\
\hline CO 2 & $224-1,224(172 \%)$ & $545(-8)$ & $601(-68)$ & \\
\hline CO 3 & $67-366(51 \%)$ & $546(-7)$ & $644(-25)$ & $\begin{array}{c}\text { Flex services } \\
0.5 € / k W: 398\end{array}$ \\
\hline CO 4 & $62-336(47 \%)$ & $491(-62)$ & $592(-77)$ & $\begin{array}{c}\text { El. savings } \\
0.05 € / k W h: 69\end{array}$ \\
\hline
\end{tabular}

The economic consequences of the four control strategies are analysed, with key results in Table 5. In the analysis, it is assumed that a reduction in energy supplied to the DHW tanks also reduces electricity delivered from the grid (independent on the use of preheating or other energy use in the building).

For customers with power tariffs, it is an advantage to reduce max. hourly energy supply each month. During a year, there is a saving potential of 2,028 euros when moving from the base case to $\mathrm{CO} 1$.

With the conditions in this work, the daily difference in spot prices seem too low to justify a management system focusing on spot price savings. It was not achieved lower spot price with CO 2 than the other control options, using spot prices during the 23 days measurement period in 2019. Spot prices vary, and if using 2021-prices for the same dates (not adjusting for change of weekdays, and assuming that the CHW habits are not directly dependent on spot prices), the savings increase from 8 euro to 68 euro during the periode, compared to base case. Spot price savings may be combined with other control options. In the future, also
Norwegian grid tariffs may depend on time of day, which may increase the savings.

It is challenging to estimate the potential income from flexibility services in $\mathrm{CO} 3$, since related tariffs are not yet existing in Norway. If assuming an activation reward of 0.5 euro $/ \mathrm{kW}$ each flexible hour, using the hourly energy supply in CO 1 as the reference, a reduction from $28 \mathrm{~kW}$ to $0 \mathrm{~kW}$ during a peak hour will generate 14 euro. For two peak hours each weekday only, the potential income during the 23 days is 398 euro (or 6,898 euro/year).

If solar energy is available, either thermal or electric, the average DHW loads in the case building fit well with the potential solar energy production, even if the whole demand cannot be covered, such as the morning loads during weekdays. Larger storage volume would increase the self-consumption potential of solar energy.

The analysis in this article uses a simple inputoutput storage tank model, with energy flows in and out of the tank. RBC can yield significant improvements with regards to demand response and flexibility [21]. $\mathrm{RBC}$ is also easy to implement, with few requirements for historic data and control system. However, RBC may lead to non-optimal solutions, since the control rules are predefined [17]. In future work, more advanced analyses are planned. The internal state of the storage tank will then be included, with temperature levels in the tank. In addition, optimalisation options will be introduced. In general, Model Predictive Control (MPC) is expected to further improve the results [21], [25], optimizing DHW operation by modelling future DHW need, technological constraints, and additional influencing parameters. In this article, we have not separated between the preheating and electricity heating systems, thus analysing the total DHW heating and storage capacity only. In real life, it would normally be an advantage to increase the preheating share of the system A deeper analysis of technical options, control algorithms and economic consequences is intended in further studies.

\section{Conclusion}

The research question of this work is: How can an apartment building reduce energy costs by shifting aggregated DHW energy loads in time, provided a limited storage volume? The case study is a building with 56 apartments. The potential for energy flexibility is simulated for a base case and four RBC options, based on hourly timesteps. The flexibility capacity of DHW systems is largely based on the volume of the storage tank. In the analysis, the volumes of the tanks are limited to the actual sizes available in the case study.

The economic analysis shows that for customers with power tariffs, it is an advantage to reduce the maximum hourly energy supply. This can be done by setting a maximum power level for delivered energy. The power level should be high enough to avoid shortterm power jumps, which would increase the tariff costs. When hourly values are used as a basis for setting the power level, a safety margin should be included, since there are variations within an hour. A management 
system with maximum power level can be combined with other control options, such as spot price savings or flexibility services. With the conditions in this work, the daily difference in spot prices is too low to justify a management system focusing on spot price savings alone. It is possible for apartment buildings to provide flexibility services to the DSO by avoiding to use energy for DHW during peak load hours in the grid. If so, the power tariffs for the building may increase and investments in larger storage volume may be needed. The interests in offering flexibility services will therefore depend on the economic conditions for the services.

The results of the study support the theory that aggregated DHW need is a significant source of flexible energy use in Norwegian apartment buildings. A deeper analysis of technical options, control algorithms and economic consequences is intended in further studies.

The work presented in this paper was developed within the Institute PhD grant (272402) at SINTEF, the project "Energy for domestic hot water in the Norwegian low emission Society" (VarmtVann2030) (267635) and the Research Centre on Zero Emission Neighbourhoods in Smart Cities (257660). The authors gratefully acknowledge the support from the partners and the Research Council of Norway.

\section{References}

[1] Y. Chen, P. Xu, J. Gu, F. Schmidt, and W. Li, "Measures to improve energy demand flexibility in buildings for demand response (DR): A review," Energy Build., vol. 177, pp. 125-139, 2018.

[2] M. Z. Pomianowski, H. Johra, A. MarszalPomianowska, and C. Zhang, "Sustainable and energy-efficient domestic hot water systems: A review," Renew. Sustain. Energy Rev., vol. 128, no. April, p. 109900, 2020.

[3] P. D. Lund, J. Lindgren, J. Mikkola, and J. Salpakari, "Review of energy system flexibility measures to enable high levels of variable renewable electricity," Renew. Sustain. Energy Rev., vol. 45, pp. 785-807, 2015.

[4] H. T. Walnum, "VarmtVann2030 - Energi (to be published)," 2021.

[5] A. Balint and H. Kazmi, "Determinants of energy flexibility in residential hot water systems," Energy Build., vol. 188-189, pp. 286-296, 2019.

[6] T. Ericson, "Direct load control of residential water heaters," Energy Policy 37 3502-3512, 2009.

[7] A. Heidari, N. Olsen, P. Mermod, A. Alahi, and D. Khovalyg, "Adaptive hot water production based on Supervised Learning," Sustain. Cities Soc., vol. 66, p. 102625, 2021.

[8] L. Gelažanskas and K. A. A. Gamage, "Forecasting hot water consumption in residential houses," Energies, vol. 8, no. 11, pp. 12702-12717, 2015.

[9] E. Fuentes, L. Arce, and J. Salom, "A review of domestic hot water consumption profiles for application in systems and buildings energy performance analysis," Renew. Sustain. Energy Rev., vol. 81, no. April 2017, pp. 1530-1547, 2018.
[10] D. Ivanko, Å. L. Sørensen, and N. Nord, "Selecting the model and influencing variables for DHW heat use prediction in hotels in Norway," Energy Build., vol. 228, p. 110441, 2020.

[11] European Committee for Standardization, "EN ISO 52000-1 Energy performance of buildings." 2017.

[12] "Elvia Effekttariff - bedriftskunder," 2021. https://www.elvia.no/nettleie/alt-omnettleie/nettleiepriser-og-effekttariff-for-bedrifter-ioslo-og-viken.

[13] Nordpool, "Day-ahead prices," 2021. https://www.nordpoolgroup.com/Marketdata1/Dayahead/Area-Prices/NO/Hourly.

[14] B. A. Bremdal, P. Olivella-Rosell, J. Rajasekharan, and I. Ilieva, "Creating a local energy market," CIRED - Open Access Proc. J., vol. 2017, no. 1, pp. 2649-2652, 2017.

[15] Å. L. Sørensen, I. Sartori, K. B. Lindberg, and I. Andresen, "Analysing electricity demand in neighbourhoods with electricity generation from solar power systems: A case study of a large housing cooperative in Norway," in IOP Conference Series: Earth and Environmental Science, 2019, vol. 352 , no. 1 .

[16] SSB, "09387: Kraftpris, nettleie og avgifter for husholdninger," 2021

https://www.ssb.no/statbank/table/09387.

[17] J. Clauß, S. Stinner, I. Sartori, and L. Georges, "Predictive rule-based control to activate the energy flexibility of Norwegian residential buildings: Case of an air-source heat pump and direct electric heating," Appl. Energy, vol. 237, no. October 2018, pp. 500-518, 2019.

[18] J. Deng, Q. Wei, M. Liang, S. He, and H. Zhang, "Does heat pumps perform energy efficiently as we expected: Field tests and evaluations on various kinds of heat pump systems for space heating," Energy Build., vol. 182, pp. 172-186, 2019.

[19] SINTEF, "Project VarmtVann2030," 2021. https://www.sintef.no/varmtvann.

[20] H. Taxt Walnum, Å. L. Sørensen, B. Ludvigsen, and D. Ivanko, "Energy consumption for domestic hot water use in Norwegian hotels and nursing homes," IOP Conf. Ser. Mater. Sci. Eng., vol. 609, no. 5,2019

[21] T. Q. Péan, J. Salom, and R. Costa-Castelló, "Review of control strategies for improving the energy flexibility provided by heat pump systems in buildings," J. Process Control, vol. 74, pp. 35-49, 2018.

[22] "Oslo solkart," 2021. https://od2.pbe.oslo.kommune.no/solkart/.

[23] S. Pfenninger and I. Staffell, "Long-term patterns of European PV output using 30 years of validated hourly reanalysis and satellite data," Energy, vol. 114, pp. 1251-1265, 2016.

[24] D. Ivanko, H. Taxt Walnum, Å. Lekang Sørensen, and N. Nord, "Analysis of monthly and daily profiles of DHW use in apartment blocks in Norway," E3S Web Conf., vol. 172, pp. 1-7, 2020.

[25] J. Drgoňa et al., "All you need to know about model predictive control for buildings," Annu. Rev. Control, vol. 50, no. August, pp. 190-232, 2020. 